This article has been accepted for publication in the Journal of Medical Ethics 2021 following peer review, and the Version of Record can be accessed online at doi.org/10.1136/medethics2020-106998.

Mr. Joona Räsänen ${ }^{1,2} \&$ Dr. Anna Smajdor ${ }^{1}$

1. Department of Philosophy, Classics, History of Art and Ideas, University of Oslo, Oslo, Norway

2. Faculty of Social Sciences, Tampere University, Tampere, Finland

\title{
The Complex case of Ellie Anderson
}

Abstract:

Ellie Anderson had always known that she wanted to have children. Her mother, Louise, was aware of this wish. Ellie was designated male at birth, but according to news sources, identified as a girl from the age of three. She was hoping to undergo gender reassignment surgery at 18, but died unexpectedly at only 16, leaving Louise grappling not only with the grief of losing her daughter, but with a complex legal problem. Ellie had had her sperm frozen before starting hormone treatment, specifically so that she would retain the chance of becoming a parent after her gender reassignment. Ellie had considered what might happen to the sperm if she died and was adamant that her children should be brought into the world. She made her mother promise to ensure that this would happen. But according to UK law, Ellie's mother has no legal right to retain her sperm, or to use it to fulfil Ellie's wishes. In this paper we raise several key ethical questions on this case, namely: does a refusal to bring Ellie's children into the world wrong her posthumously? Is Ellie's mother morally entitled to use her daughter's sperm as Ellie wished? Should the fact that Ellie was a minor at the time of her death or the fact that she was transgendered undermine her wish to have children? Can Ellie become a parent posthumously? We consider how these complex ethical questions could be approached. 


\section{Introduction}

Ellie Anderson ${ }^{1}$ died unexpectedly in July 2020 at the age of 16. She was designated male at birth, but from a young age had identified as a girl. At the time of her death she had started taking hormone blockers. She was planning to undergo surgical gender transition eventually. Prior to starting drug treatment, she had had her sperm frozen so that she could have children one day. Ellie's mother, Louise, promised her daughter that if anything were to happen to her, her children would be brought into the world. ${ }^{\mathrm{i}}$ But when Ellie died at only 16, Louise found she had no legal right to access Ellie's sperm. Although Ellie had taken steps to preserve the possibility of reproduction, it seemed her wishes would be thwarted.

At the time of writing, Louise is planning to bring her case to court. According to the news reports, she wants access to Ellie's sperm so that she can find a surrogate and an egg donor, and thus create the child that Ellie longed for. In the meantime, Ellie's sperm will be stored until the outcome of her mother's case is determined.

In this paper, we consider what ethical issues are at stake in this case. We identify the following ethical questions and explore possible ways to answer them.

Is it wrong to ignore someone's wishes after they have died?

What duties does Ellie's mother have with regard to the fulfilment of her daughter's wish?

Could Ellie's sperm be treated as 'donor' sperm?

What is the content of Ellie's wish? (Can one become a parent posthumously, or only reproduce?)

What role, if any, does Ellie's transgender status have in this case?

\section{Is it possible to wrong someone after their death?}

There are a number of cases in which people have sought permission to use a dead person's gametes in order to have children. In the majority of these cases, the gametes had either not yet been taken (so were removed without their consent), ${ }^{2}$ or had been taken, but there had

\footnotetext{
${ }^{i}$ The exact content of the promise is not clear. In the media outlets, Louise told that "She [Ellie] had made me promise that if anything were to happen to her, her children would be brought into the world." For the purpose of the paper, we assume that Louise simply assumed to take the necessary measures to bring Ellie's child into existence via surrogacy and perhaps adoption, not, for instance, to gestate or raise the child by herself.
} 
been no agreement as to what should happen to them in the event of that person's death. ${ }^{3}$ Thus, the consent angle of posthumous reproduction cases has been widely discussed. In this paper, we take a different approach, to consider what ethical concerns are relevant, setting aside the question of consent.

Some might argue that a dead person cannot be made worse-off, and therefore cannot be wronged. If so, we have no moral reason to concern ourselves about the fulfilment of people's wishes once they are dead. This is not an uncommon view; it has been argued by several philosophers. ${ }^{4}{ }^{5}$ Nevertheless, it is clear that many - even most - living people have concerns and desires that extend beyond their lives. Some might want to be organ donors. Others may have a wish to be buried in a particular place. Still others may want their wealth to go to particular individuals or institutions.

Our social, ethical and legal frameworks place significant weight on our treatment of dead people. These frameworks are premised at least in part on the idea that there are some things we should and should not do with regard to the dead. For example, a person's will is legally (and arguably morally) binding. The use of people's bodies without their previous consent is widely condemned, and in many cases, prohibited by law. ${ }^{2}$ Thus, for those who believe the dead cannot be wronged, the implications are further reaching than one might imagine.

Let us consider an example: the case of the "Irish Giant", Charles Byrne. Byrne lived in London in the 1780s. He was so tall that people paid money to get a look at him. Byrne was aware that a local surgeon - John Hunter - wanted his enormous body for dissection and display after his death. Byrne was horrified by this prospect. It was of supreme importance to him that his body should be kept intact after his death. Realising that his health was failing, he consulted with friends, and made arrangements that on his death, his body would be sealed in a lead coffin, and buried at sea. However, Byrne's wishes were thwarted; Hunter managed to get hold of the dead giant's body and exhibit his skeleton in the Hunterian Museum where it remained on display for nearly two centuries. ${ }^{\text {ii }}$

Intuitively it seems ethically wrong that Hunter put Byrne's skeleton on display, knowing that Byrne was adamantly opposed to this. In 2011, when Byrne's skeleton was still on display in

\footnotetext{
${ }^{\text {ii }}$ History is full of similar stories. Legendary jazz musician Charlie "Bird" Parker was buried about 1200 miles away from where he wanted to be buried. Bird wanted to be buried in Long Island, New York, next to his daughter - instead, he was buried in Lincoln Cemetery, Missouri - where Parker, when alive, faced deep, systemic racism and discrimination.
} 
a different museum, it was argued that his burial wishes should finally be respected. ${ }^{6}$ To explain the wrongness in cases like Byrne's, some ethicists have argued that it is indeed possible to harm or wrong people after their death. ${ }^{7,8,9,10}$ If there is some kind of prima facie obligation to respect the wishes of people after their death, it remains to be established what kind of reasons might outweigh or support such obligations, and upon whom these duties might fall. We can then consider how these factors weigh in favour of or against a duty to respect Ellie's wish to have children. ${ }^{\text {iii }}$ At least a few initial considerations come to mind here: the strength of the desire, difficulty in achieving it and a question of how reasonable the desire is. To take this latter condition first, we might think that Byrne's wish to control what happens (or doesn't happen) to his dead body is fairly reasonable. But let us suppose that Byrne had wanted to be cremated and his ashes to be eaten by a particular individual. Such a strange or even bizarre wish might hold less sway. Particularly if it requires action on the part of other individuals.

The degree of difficulty in fulfilling the wish is also significant. Byrne's wish was relatively straightforward; he wanted to be buried at sea. However, if he had wanted to be buried in Australia, this would raise questions about who would pay for the expense, who would transport his body, etc. These difficulties might weigh against the case for claiming that someone has an obligation to fulfil his posthumous wish. That is, the wish can be seen as conferring a prima facie obligation that is outweighed because it is unreasonably demanding.

Finally, if we imagine that Byrne only had a mild preference for being buried at sea rather than being put on display at the museum, the degree to which this desire could translate into a moral obligation on the part of others would seem more questionable.

What about Ellie? Her desire was to have children. It is uncontroversial to note that the desire for offspring can be extremely powerful. According to her mother, this was very much the case for Ellie. ${ }^{11}$ Not only did Ellie express her wishes to have children explicitly, she also took decisive actions towards ensuring that this wish could one day be realised. The newspaper reports highlight the fact that Ellie saved up her pocket money and birthday and Christmas money for years to cover the costs of finding a surrogate mother to gestate her child. Her wish was not just an unformed longing: she specifically wanted a boy and a girl

\footnotetext{
iii Obviously, the case of the Irish Giant is not very analogous with the case of Ellie Anderson, however, the Irish Giant case shows that at least sometimes it is, arguably, possible to wrong people even after their death. That is a feature that seems to be morally relevant also with Ellie.
} 
and even had names picked out for them. She froze her sperm at the age of 14 because it was so important to her that she should have children, and she knew that her plans for gender reassignment would leave her infertile.

Ellie also left strict instructions to her mother that if anything happened to her, she wanted her children brought into the world. Based on all the available evidence, the strength of Ellie's desire seems to go much further than a mild preference. This may give us a prima facie reason at least for regarding it as being morally significant.

Is Ellie's wish to have children posthumously relatively easy or difficult for others to fulfil? For Ellie's goal to be achieved, we would need, in addition to preventing Ellie's sperm from being destroyed, an egg donor and a surrogate mother at least. Both of these involve significant effort and a degree of medical risk. Aside from the risks themselves, both egg donation and surrogacy raise their own set of ethical questions in an already complicated context. $^{12,13,14,15}$

What about the content of Ellie's wish, or its 'reasonableness'? On one level, it is very normal to wish to have children. There is nothing bizarre or incomprehensible about such wishes; indeed, their all-pervadingness makes it hard to question them. Some people would argue that wishes concerning reproduction have a special moral significance. That is, they engage the question of reproductive rights and autonomy. Such rights may continue to be of moral significance even after one's death. Yet even John Robertson, one of the most ardent proponents of reproductive autonomy, notes that this principle in itself cannot yield simple answers to questions of posthumous reproduction. We need to balance the principle against other ethical considerations. ${ }^{16}$ Not only this, but the very concept of 'reproductive autonomy' becomes difficult to interpret in changing medical and social contexts, in ways that perhaps Robertson did not initially envisage. One problem is that discussions of reproductive autonomy have commonly focused on adults, rather than children or adolescents. In recent years, scholars have begun to address this gap, ${ }^{17}$ but it remains a rather under-theorised area in the literature.

In summary, we have reason to suppose that Ellie's wish was more than a mild preference. We know that the longing for children is something that is usually regarded as being reasonable, rather than being bizarre or unique and that many people regard this wish as having a special moral value. Nevertheless, carrying out Ellie's wishes may be difficult, if it 
involves finding surrogates and egg donors. We do not attempt a definitive resolution here, but aim simply to show some of the factors that might be taken into account.

A final point to make here is that of course people's reproductive wishes in particular, have effects on other people, namely future children. In this article, we do not discuss whether bringing Ellie's children into world would harm or wrong them; the question of whether one can be harmed by being brought into existence is contentious. ${ }^{18,19}$ As Hodson and Parker put it in the context of post-mortem sperm donation, posthumous conception may come with some disadvantages for offspring, but their suffering would have to be extraordinarily severe to be incompatible with a worthwhile life. ${ }^{20}$ Our focus here is therefore not on whether Ellie's child would be harmed, but on whether her wishes have moral force once the question of harm to offspring is set aside.

\section{What duties does Ellie's mother have in regard to Ellie's wishes?}

If we agree that there are prima facie reasons for thinking posthumous wishes should be fulfilled, the question remains as to who is responsible. Reproductive wishes are complex specifically because they (almost) invariably engage others.If Ellie had had a partner at the time she died, perhaps that would be the obvious answer (subject, of course, to the partner's agreement). But since she did not, perhaps Louise, Ellie's mother should be responsible for fulfilling Ellie's wish. This seems especially compelling since Ellie specifically told her mother that if anything were to happen to her, she wanted her children to be brought into the world. ${ }^{\text {iv }}$

The news reports emphasise the promise that Ellie's mother made to her daughter. A promise to ensure that Ellie's offspring would come into the world. All other things being equal, it makes sense to think of a promise as conferring an obligation on the person who makes it, and indeed, this is why the newspapers highlight it.

However, promise-making is a complex business. For a start, someone might feel coerced into promising something. Death-bed promises may be a good example of cases where a degree of

\footnotetext{
iv One might object that Louise has a conflict of interest since she would be the child's grandmother. However, Louise also has other children who will likely have children so this is not her only chance to have grandchildren. Thus, we think that Louise truly has her daughter's wish in mind although it could be possible that Louise also longs for a grandchild in Ellie's memory.
} 
emotional pressure is brought to bear on the promiser. In such instances, we might feel that there is less of a moral obligation, if there is any at all.

Of course, there are also questions to ask about whether the promiser does something unethical in making a commitment that she cannot or will not fulfil. From a Kantian perspective, no amount of emotional pressure would justify making a promise that is in itself unethical, or that one knows one has no intention of carrying out. A promise that cannot be kept cannot be morally binding, but it may nevertheless be wrong to enter into such a contract.

In Louise's case, we have no reason to suppose that she was reluctant to make the promise, or that she did not intend to fulfil it. However, the promise could not be fulfilled unless the law permitted it. Perhaps Ellie's mother intended to challenge, and change the law. Or perhaps she was not aware that her promise to Ellie would not be possible. Either way, in making this promise, she ended up with an obligation that she has not been able to fulfil. Was she wrong to assure Ellie that her sperm would be used to create offspring? How far is it the responsibility of a person who makes a promise to be aware of the factors that might make it difficult or impossible to keep it? Or should this responsibility fall on the person who asks for the promise?

It might seem harsh to blame Ellie's mother here. People make promises loosely all the time. However, what is interesting about Ellie's request and Louise's promise, is that very specific steps had already been taken to preserve Ellie's sperm; discussions had happened about the possibility of Ellie's death. Yet these discussions appear not to have found their way into the actual process of stipulating what should happen to the sperm.

Ellie could have asked the clinic staff about the possibility of assigning the sperm to her mother's 'custody' in the event of her death. If she had explored this avenue, she would either have been told that the law does not allow for this, or have been offered a way to achieve her wishes. But Ellie was, of course, a teenager. ${ }^{v}$ And a teenager undergoing a profoundly significant transition in her life. It is perhaps understandable that she did not think of these possibilities. Ellie's mother - as an adult, and as the one who made the promise - might on this view, have greater responsibility for having failed to establish whether her daughter's

\footnotetext{
$\checkmark$ We refer to Ellie as a teenager, although she was 16 and gave evidence of significant maturity. In paediatrics Ellie could be refered to as a young person. We thank anonymous referee for this remark.
} 
wishes could in fact be met. However, given the legal complexity of the situation, perhaps it is unreasonable to expect that either of the two parties to have a deep understanding of it. ${ }^{\mathrm{vi}}$

Nevertheless, it is important to note that the legal framework that permits 'fertility preservation' measures for children and adults ought also to make provision for what happens when these children die, or lose capacity. Currently the law, and the medical guidance seem inadequate to deal with the emerging challenges in this area. Arguably, this results in poor treatment of people like Ellie, who freeze gametes in the belief that they will have jurisdiction over what happens to them, when in reality, they have no such control. Thus, our conclusion here is that people should think carefully about what they ask of others, and about what commitments they undertake, but that neither Ellie nor her mother could have been expected to have an in depth knowledge of the law, or medical practice in this area.

Aside from the question of impossible promises, there may also be some things that one simply should not undertake to do for another person. Thus, a promise to do something that is inherently immoral should not be made, and if it is made should not be fulfilled.

There are a number of potential grounds on which Louise's promise might be viewed as inherently unethical. Firstly, it may be that the fulfilment of Ellie's wishes would harm or wrong other people. Ellie's request also entails that other individuals will be brought into her reproductive project. For Ellie's sperm to result in a child, an egg donor and a surrogate will be required. As noted before, both egg donation and surrogacy are regarded as being unethical by some, for a variety of reasons. If we look simply at the question of harm, it is clear that both egg donation and surrogate pregnancy carry risks to those involved. Egg donation is a surgical intervention that is usually preceded by a phase of hormonal suppression and stimulation. All of these elements carry a degree of physical risk. Surrogacy of course entails all the usual risks of pregnancy, which are significant, though commonly underplayed. When women choose to undergo these risks in the pursuit of their own reproductive projects, some of the ethical concerns attached to them may be mitigated. However, in the case of people who undertake these risks on behalf of others, the picture is more complicated.

While we do not argue for or against these practices here, we think it worth highlighting that any promise which implicitly demands these services of others, will generate ethical scrutiny. This renders the promise still more precarious, since the ability to fulfil it depends not on the

\footnotetext{
${ }^{\mathrm{vi}}$ Although one might wonder why the staff at the clinic where Ellie's sperm was stored seem not to have contributed to her understanding of how it would/could be used after her death.
} 
individual power of the promiser, but on an array of legal, social and ethical constraints on one hand, and on the contingent possibility of finding and persuading willing women to serve as donors and surrogates on the other. In effect, if Louise had promised that she would find donors and surrogates in order to guarantee that Ellie's sperm would result in offspring, she was promising more than was within her power to fulfil.

A further question arising from this situation concerns the person on whom a right/duty falls in relation to the wishes of someone who has died. This is a problem with the very concept of reproductive rights. Reproduction is something that cannot be taken by individuals. It involves at least two people. In cases where reproduction is technologically facilitated, it may involve many more. ${ }^{21}$ In Ellie's case, her contribution to the reproductive project is only a small part of the necessary components that go towards the creation of a child. ${ }^{\text {vii }}$

\section{Reproduction or parenthood: what is the content of Ellie's wishes?}

One might claim that since women are - allegedly - adult human females ${ }^{22}$, mothers are then, adult human females with biological offspring. Therefore, Ellie's desire to become a mother cannot be achieved because she was not female. Because of this Ellie is not wronged if her children are not brought into existence. Bringing her children into existence simply does not fulfil her dream (of becoming a mother).

But from the information we are given, it is not clear that being a mother was indeed the focus of Ellie's wishes. It seems that her wishes may have been a rather tangled mix of reproductive and parenting aspirations. Whether Ellie would have been called a mother or a father, if she had children, is not necessarily relevant here, since her wish was to have children.

With an increasingly wide array of biotechnological possibilities, the connection between reproduction and parenthood has been weakened. We have a strong normative inclination in our societies to expect or even demand that those who reproduce must parent the child that they have brought into the world. Because of this, there is a conceptual difficulty in recognizing that reproduction and parenthood are not mutually entailed.

Society's normative demands, however, have kept a constant pressure on those who reproduce: they are commonly expected to parent, and frequently condemned if they fail to do so.

\footnotetext{
${ }^{\text {vii }}$ And this is before we even think about raising the child.
} 
Gamete donation has generated a social and legal need for a kind of waiver from this moral opprobrium that usually applies to reproducers who do not or cannot parent. Likewise surrogacy. These procedures however are still regarded with some suspicion and still generate moral concern. The tendency is still to regard reproduction and parenthood as being morally, if not biologically entailed.

The concepts of reproductive autonomy, reproductive rights, etc. do not focus on parenthood or parenting per se. One reason for this might be that in fact people do not have the right to parent. While people are not usually actively prevented from conceiving, or reproducing, they do have their children taken away from them if they are deemed to be inadequate or dangerous for their children. Active intervention to prevent reproduction is much more unusual.

In Ellie's case, it is possible to make a distinction between her wish to reproduce (becoming a biological parent) and her wish to be a (social) parent. Clearly, parenting will not be possible for her. But reproduction remains feasible. Arguably, if Ellie had a partner who was planning to parent their offspring, the separation would not be so striking. But this is not the case. Thus, all that remains for Ellie is the possibility that she will reproduce despite being dead. That is, her genetic material may be transmitted to a child. Is this kind of wish one that we should afford moral significance to? This is important, since any other wish that Ellie may have had concerning being a social parent, or parenting, is simply not within her mother's or anyone else's power to fulfil.

\section{Could Ellie's sperm be treated as 'donor' sperm?}

We have noted that there could be difficulty in finding surrogates and egg donors to fulfil Ellie's wishes. However, Ellie could still reproduce posthumously through sperm donation. This way, any ethical worries related to surrogacy specifically could be assuaged, since whoever gestated 'Ellie's' baby would also be gestating her own child.

At first glimpse, this might seem an ideal solution for people like Ellie who die leaving gametes in storage. Not only would Ellie's wishes be fulfilled, but the parenting aspirations of others would also be fulfilled.

However, there is a legal and ethical difficulty with this apparently pleasing solution. That is that donation, whether or reproductive tissue or other body parts, usually requires the consent of the donor. While Ellie had stipulated that she wanted her sperm to be used to create 
offspring, she had not, according to the news reports, expressed any desire to donate that sperm.

In any case, it may be felt by those who read this suggestion that although gamete donation might fulfil the wishes of the recipient, there is no reason to think that Ellie herself would have been happy with this option. Ellie's mother is not fighting for the right to donate Ellie's gametes, but to obtain them herself so that she can identify a surrogate, an egg donor, and arrange for the birth of a child or children. We are not told who will parent the offspring, but one possibility is that it would be Louise herself.

Yet if Louise raises Ellie's biological child, this also fails to fulfil Ellie's wish insofar as it was a wish to be a parent; all it fulfils is the wish to reproduce - a wish that would be equally effectively realised through gamete donation.

\section{What is the significance of Ellie's status as a transgendered 16 year old ?}

We know that Ellie had identified as a girl from a young age, and was in the process of hormonal transition, with an intention of undergoing surgical transition. The term 'transition' might imply that Ellie was not yet a woman, since she was waiting for the final procedures that would make her one. This raises the question of whether someone who is waiting for gender transition procedures, or is currently undergoing them, is male or female, or neither. This is important, given that the legal and medical frameworks surrounding reproduction and parenthood are still strongly gendered. In UK law, and many other jurisdictions, only a woman who gives birth to a child is the default mother.

So what was Ellie at the time of her death? A boy who identified as a girl? Or already a girl, with male sex organs and gametes? Or perhaps a potential girl? These questions have a bearing on what Ellie would legally have been entitled to do. As a male, it is unlikely she would have been able to access fertility treatment in the UK to have a child without a partner. ${ }^{\text {vii }}$

There is an ongoing debate both on how much chronological age matters when it comes to health care decisions ${ }^{23,24}$ and rights ${ }^{25,26}$ and whether adolescents can consent. ${ }^{27}$ We do not consider in detail whether Ellie's age plays a role here. We assume that since children under the age of 16 can consent to their own treatment if they're believed to have enough

\footnotetext{
viii Although in theory a private clinic could offer treatment to a single man, we don't think it would happen in practice, because surrogacy would be a required part of the process, and this isn't supported in UK law.
} 
intelligence, competence and understanding to fully appreciate what's involved in the treatment (known as Gillick competence. ${ }^{28,29,30)}$ it is at least plausible that, Ellie, at the age of 16 could consent to have children.

A 16 year old boy has no default right to reproduce. If he conceives a child with a partner, he may acquire the right/obligation to provide for that child. A 16 year old boy who needed medical assistance to reproduce would be very unlikely to receive it. We know of no such cases where this has happened in the UK. However, Ellie did not identify as a boy, but as a girl. As a girl, Ellie would have been regarded as the mother of any child she gave birth to, according to the law. However, this legal right can be overridden, if a person is not regarded as having the capacity to meet a child's needs. It may make more sense in both cases to regard this legal right as being based in the law's reluctance to intervene in people's bodily autonomy. That is, the law very seldom sanctions the kind of physically coercive treatment that would be necessary to bring about or prevent a 'natural' pregnancy. Only as someone who could 'naturally' get pregnant would Ellie have been able to ensure that she would have children at the age of 16 .

Since Ellie was not able to get pregnant naturally, any reproductive projects she formed would have to be facilitated through the involvement of medical intervention as well as reproductive partners, donors or surrogates. These, the law does not undertake to provide treatment simply on the basis that people's reproductive wishes should be fulfilled. Rather, treatment is provided - at least in theory - on the basis of medical need. One argument here might be that way the law responds to 'natural' reproduction is discriminatory. It is far easier for an adult, fertile, cisgender heterosexual person to become a parent than for someone in Ellie's position. If one claims that Ellie should not be allowed to have children posthumously solely because of her being a transgendered person this would seem to imply that Ellie, or other transgendered people for that matter, should not be allowed to have children while alive either. Some countries, such as Finland, do require infertility from citizens who want to change their legal gender. However, many have deemed such practice unethical and against reproductive justice. ${ }^{31}$

\section{Conclusion}

In this article, we have considered what ethical issues raised are present in the case of Ellie Anderson, a transgender girl who wanted to have children posthumously. Our aim in this 
paper has not been to solve the case of Ellie Anderson. But hopefully we have managed to illustrate how these complex ethical questions could be approached.

${ }^{1}$ Mother in legal fight to save dead transgender daughter's sperm. BBC News 25. Aug. 2020. <https://www.bbc.com/news/uk-scotland-glasgow-west-53889359> Accessed 8 Sept. 2020.

${ }^{2}$ Smajdor A. Perimortem gamete retrieval: should we worry about consent?. Journal of Medical Ethics. 2015 Jun 1;41(6):437-42.

${ }^{3}$ Evans JB. Post-mortem Semen Retrieval: A Normative Prescription for Legislation in the United States. Concordia L. Rev. 2016;1:133.

${ }^{4}$ Callahan JC. On harming the dead. Ethics 1987;97.2:341-52

${ }^{5}$ Harris J. Organ procurement: dead interests, living needs. J Med Ethics 2003;29:130-4.

${ }^{6}$ Doyal L, Muinzer T. Why the Royal College of Surgeons should respect the wishes of "the Irish giant". Br Med J 2011;343:1290-1292.

${ }^{7}$ Levenbook BB. Harming Someone after His Death. Ethics 1984;94:407-419.

${ }^{8}$ Pitcher G. The Misfortunes of the Dead. Am Philos Q 1984;21:183-188.

${ }^{9}$ Feinberg J. Harm to Others. Oxford University Press, 1984.

${ }^{10}$ Boonin D. Dead Wrong - The Ethics of Posthumous Harm. Oxford University Press, 2020.

${ }^{11}$ Transgender Scots teen saved up birthday and Christmas money for dream of having babies before her shock death. The Scottish Sun. 25. Aug. 2020.

<https://www.thescottishsun.co.uk/news/scottish-news/5966290/ellie-anderson-mum-spermgrandchild-transgender-children/> Accessed 8 Sept. 2020.

${ }^{12}$ Daniels KR. To give or sell human gametes - the interplay between pragmatics, policy and ethics. J Med Ethics 2000;26:206-211.

${ }^{13}$ Wilkinson, S. The exploitation argument against commercial surrogacy. Bioethics 2003;17:169-187.

${ }^{14}$ Tieu MM. Altruistic surrogacy: the necessary objectification of surrogate mothers. $J$ Med Ethics 2009;35:171-175.

${ }^{15}$ Overall, C. Reproductive 'Surrogacy' and Parental Licensing. Bioethics 2015;29: 353-361.

${ }^{16}$ Robertson, J. A. (1994). Posthumous reproduction. Indiana Law Journal, 69(4), 1027-1066.

${ }^{17}$ Cutas D. Should Parents Take Active Steps to Preserve Their Children's Fertility?. In

Parental Responsibility in the Context of Neuroscience and Genetics 2017 (pp. 189-205). Springer, Cham.

${ }^{18}$ Parfit D. Reasons and Persons. Oxford, Oxford University Press; 1984.

${ }^{19}$ Smajdor A. How useful is the concept of the 'harm threshold'in reproductive ethics and law?. Theoretical Medicine and Bioethics. 2014 Oct 1;35(5):321-36.

${ }^{20}$ Hodson N, Parker, J. The ethical case for non-directed postmortem sperm donation. J Med Ethics 2020;46:489-492.

${ }^{21}$ Cavaliere G, Palacios-González C. Lesbian motherhood and mitochondrial replacement techniques: reproductive freedom and genetic kinship. J Med Ethics 2018;44:835-842.

${ }^{22}$ Byrne A. Are women adult human females? Philos Stud 2020. https://doi.org/10.1007/s11098-019-01408-8.

${ }^{23}$ Lippert-Rasmussen K, Petersen TS. Age change, official age and fairness in health. $J$ Med Ethics 2020;46:634-635.

${ }^{24}$ Räsänen J. Age change in healthcare settings: A reply to Lippert-Rasmussen and Petersen. $J$ Med Ethics 2020;46:636-637.

${ }^{25}$ Räsänen J. Moral case for legal age change. J Med Ethics 2019;45:461-464.

${ }^{26}$ Räsänen J. Age and ageing: What do they mean? Ratio doi: 10.1111/rati.12284. 
${ }^{27}$ Brierley J, Larcher V. Adolescent autonomy revisited: clinicians need clearer guidance. $J$ Med Ethics 2016;42:482-485.

${ }^{28}$ Griffith, R. What is Gillick competence? Hum Vaccin Immunother 2016;12:244-247.

${ }^{29}$ Hunter D, Pierscionek BK. Children, Gillick competency and consent for involvement in research. J Med Ethics 2007;33:659-662.

${ }^{30}$ Zimmerman, N. Gillick Competence: An Unnecessary Burden. New Bioeth 2019;25:78-93.

${ }^{31}$ Honkasalo J. Unfit for Parenthood? Compulsory Sterilization and Transgender

Reproductive Justice in Finland. J int women's stud 2018;20:40-52. 